\title{
FAK integrates growth-factor and integrin signals to promote cell migration
}

\author{
David J. Sieg* ${ }^{*}$, Christof R. Hauck* †, Dusko Ilicł, Candice K. Klingbeil* , Erik Schaefer§, Caroline H. \\ Damskył and David D. Schlaepfer* $q$ \\ ${ }^{*}$ Department of Immunology, IMM 26, The Scripps Research Institute, 10550 N. Torrey Pines Road, La Jolla, California 92037, USA \\ ¥Department of Stomatology, University of California San Francisco, San Francisco, California 94143, USA \\ $\S Q C B-A$ Division of BioSource International, Hopkinton, Massachusetts 01748, USA \\ ge-mail: dschlaep@scripps.edu \\ $\dagger$ These authors contributed equally to this work
}

\begin{abstract}
Here we show that cells lacking focal adhesion kinase (FAK) are refractory to motility signals from platelet-derived and epidermal growth factors (PDGF and EGF respectively), and that stable re-expression of FAK rescues these defects. FAK associates with activated PDGF- and EGF-receptor (PDGFR and EGFR) signalling complexes, and expression of the band-4.1-like domain at the FAK amino terminus is sufficient to mediate an interaction with activated EGFR. However, efficient EGF-stimulated cell migration also requires FAK to be targeted, by its carboxy-terminal domain, to sites of integrin-receptor clustering. Although the kinase activity of FAK is not needed to promote PDGF- or EGF-stimulated cell motility, kinase-inactive FAK is transphosphorylated at the indispensable Src-kinase-binding site, FAK Y397, after EGF stimulation of cells. Our results establish that FAK is an important receptor-proximal link between growth-factorreceptor and integrin signalling pathways.
\end{abstract}

\section{$\mathrm{T}$} ransmembrane integrins bind to extracellular matrix proteins and generate important signals that regulate cell proliferation and migration events stimulated by receptors for soluble growth factors. Integrin and growth-factor signalling pathways can interact through several mechanisms, from membrane-proximal clustering of the two receptor types ${ }^{1,2}$ to the activation of common downstream signalling pathways ${ }^{3-5}$. Although there is a wealth of knowledge regarding the signalling pathways activated by both integrin and growth-factor receptors, little is known about how these signals are integrated by cells and whether there are common receptor-proximal control points that synchronize the execution of biological functions such as cell motility.

FAK is a non-receptor protein-tyrosine kinase (PTK) that indirectly localizes to sites of integrin-receptor clustering through $\mathrm{C}$ terminal-domain-mediated interations ${ }^{6}$ with integrin-associated proteins such as paxillin ${ }^{7,8}$ and talin ${ }^{9}$. FAK becomes phosphorylated at seven to eight different tyrosine residues in vivo after engagement of integrin with matrix proteins ${ }^{10}$. Several studies have shown that FAK functions as part of a cytoskeleton-associated network of signalling proteins, also including the Src-family PTKs, p130 ${ }^{\text {Cas }}$, Shc and Grb2, which act in combination to transduce integrin-generated signals to the ERK/JNK mitogen-activated protein (MAP) kinase cascades (reviewed in ref. 11).

Evidence indicates that tyrosine phosphorylation of FAK may be important for cell migration, as expression of the protein-tyrosine phosphatase PTEN leads to dephosphorylation of FAK and inhibition of cell motility ${ }^{12,13}$. Experiments using FAK-null cells ${ }^{14-16}$, FAK overexpression $^{17}$ and dominant-negative FAK constructs ${ }^{18}$ have established that FAK is essential for integrin-stimulated cell migration. Null mutations of the murine fibronectin ${ }^{19}$ or $f_{a} k^{20}$ genes result in a similar lethal phenotype where embryos fail to develop past day 8.5 of embryonic development because of defective gastrulation events. Cultured FAK-deficient $\left(F A K^{--}\right)$cells exhibit a rounded morphology, enhanced formation of focal contacts with matrix proteins, and migration defects ${ }^{21}$. Expression of the FAK-related PTK Pyk2 is elevated in $F A K^{-1-}$ fibroblasts, and the combined phosphorylation activities of Pyk2 and Src-family PTKs facilitate integrin-stimulated ERK2 activation in the absence of FAK ${ }^{14}$. Inter- estingly, Pyk2 does not strongly localize to focal contact sites and its overexpression does not rescue the cell-migration defects caused by the FAK mutation ${ }^{14}$. When stably re-expressed in $F A K^{-1-}$ cells, epitope-tagged FAK localizes to focal-contact sites, promotes morphology changes and reverses the integrin-stimulated migration defects ${ }^{15}$.

Here we show that FAK acts as a receptor-proximal bridging protein that links growth-factor-receptor and integrin signalling pathways. By directly comparing $F A K^{+/+}, F A K^{-/}$and FAK-reconstituted fibroblasts, we find that FAK associates with activated growth-factor receptors through its $\mathrm{N}$-terminal domain and that FAK has an important function in promoting PDGF- and EGFstimulated cell migration.

\section{Results}

FAK function is required for PDGF-stimulated cell migration. To test the importance of FAK in promoting growth-factor-stimulated cell migration, we carried out chemotaxis assays in a modified Boyden chamber with $F A K^{+/+}$and $F A K^{-/-}$fibroblasts, and with DA2 clonal fibroblasts, which re-express FAK $^{15}$ (Fig. 1). At low concentrations of PDGF $\left(2.5-10 \mathrm{ng} \mathrm{ml}^{-1}\right), F A K^{+++}$and DA2 cells, but not $F A K^{-/}$cells, readily migrated to PDGF-BB in a dose-dependent manner (Fig. 1a). The lack of migration to PDGF-BB observed in $F_{A K^{-1}}$ cells was not due to the refractory responsiveness of the PDGFR, as normal levels of PDGF-stimulated tyrosine phosphorylation $\left(10 \mathrm{ng} \mathrm{ml}^{-1}, 5 \mathrm{~min}\right)$ were detected in lysates from $F A K^{-/-}$cells (Fig. 1a).

Previous studies have shown that phosphorylation of FAK tyrosine residues increases upon cell stimulation involving growth factors, chemokines or G proteins (reviewed in ref. 11). Surprisingly, stimulation with PDGF caused only small increases in total phosphotyrosine levels in FAK and Pyk2. However, PDGF treatment induced the association of a phosphotyrosine-containing protein of relative molecular mass $190,000\left(M_{\mathrm{r}} \sim 190 \mathrm{~K}\right)$ with $\mathrm{FAK}$ in $\mathrm{FAK} \mathrm{K}^{+/+}$ and DA2 cells, but not with Pyk2 in $F A K^{-/-}$cells (Fig. 1b). Reciprocal co-immunoprecipitation experiments using antibodies to the PDGFR and lysates from starved or PDGF-stimulated DA2 cells 
a

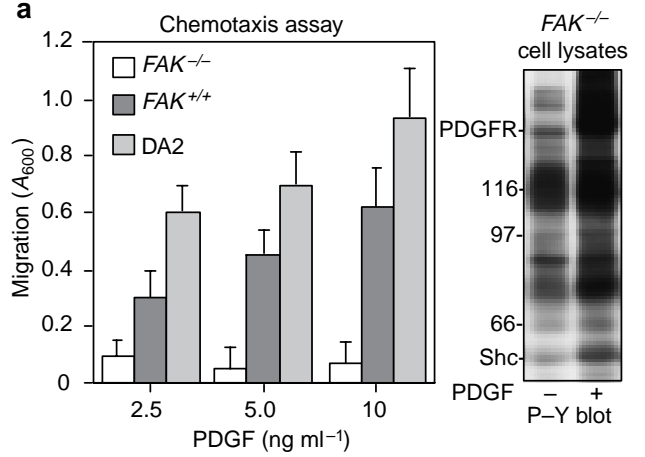

b
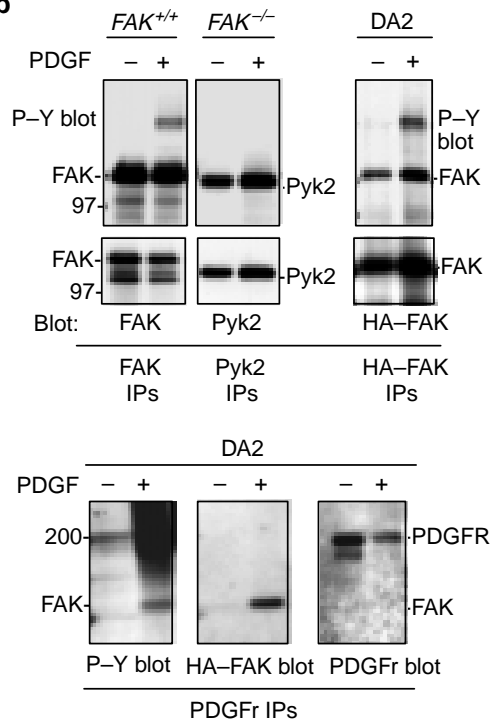
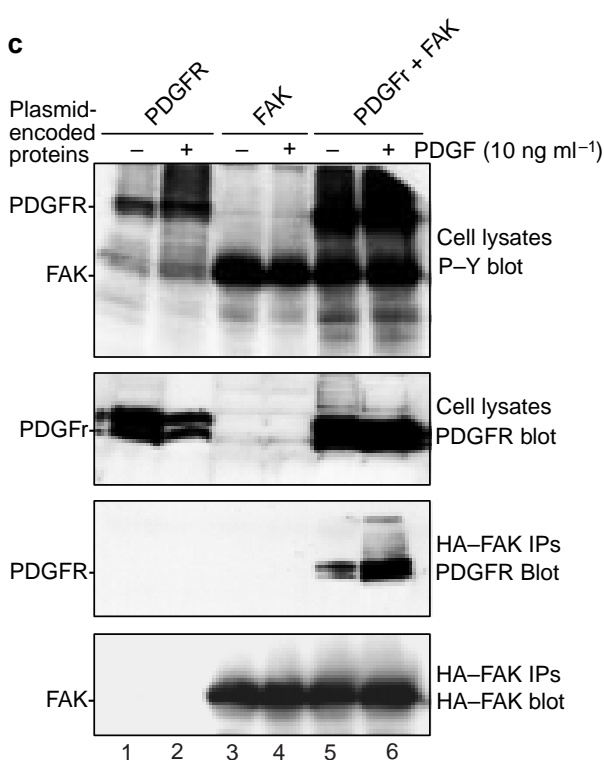

Figure 1 FAK forms a complex with the activated PDGFR and is required for PDGF-stimulated cell motility. a, In a chemotaxis assay using a modified Boyden chamber, $\mathrm{FAK}^{+++}$fibroblasts and DA2 cells migrate towards PDGF-BB whereas $\mathrm{FAK}^{-1-}$ cells do not. Values are mean \pm s.d. of at least three separate experiments. Starved $\mathrm{FAK}^{-1-}$ fibroblasts respond to PDGF-BB stimulation with enhanced tyrosine phosphorylation, as detected by blotting of cell lysates against phosphorylated tyrosine (P-Y). Numbers in the right panel represent $M_{r}$ in thousands. $\mathbf{b}$, After stimulation with PDGF-BB, a phosphotyrosine-containing protein of $M_{\mathrm{r}} \sim 190 \mathrm{~K}$ coimmunoprecipitates with antibodies to $\mathrm{FAK}$ in $\mathrm{FAK}^{+/+}$cells and antibodies to HAtagged FAK (HA-FAK) in DA2 cells, but not with antibodies to Pyk2 in $F A K^{---}$cells. HAtagged FAK associates with PDGFR immunoprecipitates (IPS) in DA2 fibroblasts after PDGF-BB stimulation. c, Transient co-transfection of PDGFR-null 293T cells shows the specific association of HA-FAK and PDGFR immunoprecipitates after PDGF-BB stimulation.

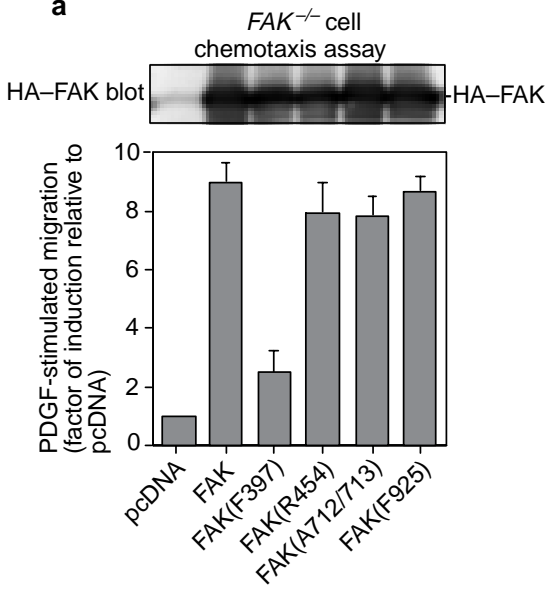

b

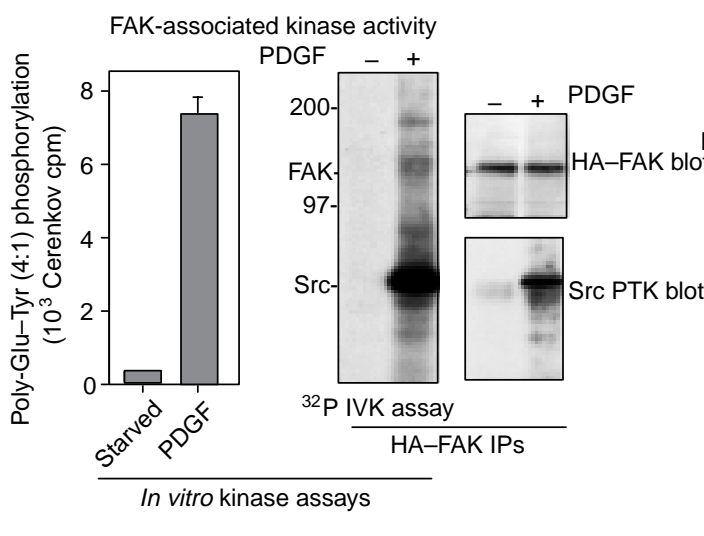

c DA2 cell

chemotaxis assay

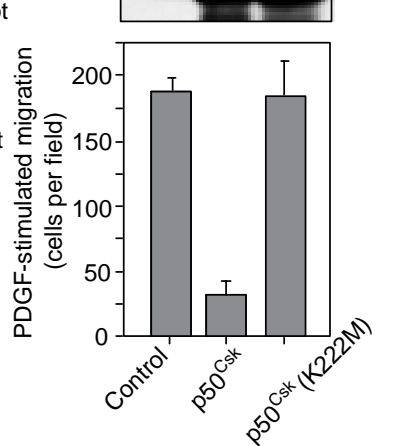

Figure 2 The FAK SH2-binding site and Src-family protein-tyrosine-kinase activity are necessary for PDGF-stimulated cell migration. a, The FAK Y397 site is necessary to enhance PDGF-stimulated migration of $\mathrm{FAK}^{-1-}$ cells, whereas kinase-inactive FAK(R454) or FAK mutants that do not bind p130 Cas (FAK(A712/713)) or Grb2 (FAK(F925)) function to promote PDGF-stimulated $\mathrm{FAK}^{-1-}$ motility. Values are means \pm s.d. of at least three separate experiments. $\mathbf{b}$, Effect of PDGF stimulation on the kinase activity of FAK, as measured by in vitro poly-Glu-Tyr phosphorylation and observed using an in vitro autophosphorylation (32P IVK) assay. The observed difference may reflect the recruitment of active Src-family PTKs to a FAK signalling complex. IPs, immunoprecipitates. Numbers in the central panel represent $M_{\mathrm{r}}$ in thousands. c, Inhibition of Src-family PTK activity by overexpression of $\mathrm{p} 50^{\text {csk }}$ but not kinase-inactive $\mathrm{p} 50^{\mathrm{csk}}(\mathrm{K} 222 \mathrm{M})$ prevents PDGF-stimulated motility of DA2 cells. Values are means \pm s.d. of two separate experiments. showed that HA-tagged FAK was tyrosine-phosphorylated and associated with PDGFR immunoprecipitates only after DA2 cells were stimulated with PDGF (Fig. 1b).

FAK forms a complex with activated PDGFR. FAK has been shown to co-immunoprecipitate with an unknown phosphotyrosine-con- taining protein of $M_{\mathrm{r}} \sim 200 \mathrm{~K}$ after cell stimulation with $\mathrm{PDGF}^{22}$. To confirm the ability of FAK and the PDGFR to associate, we transiently transfected human 293T cells, which do not express PDGFR, with expression vectors for the PDGFR $\beta$-subunit or HA-tagged FAK (Fig. 1c). 
a

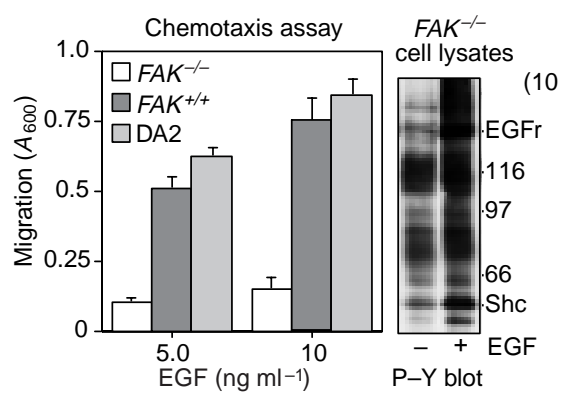

b

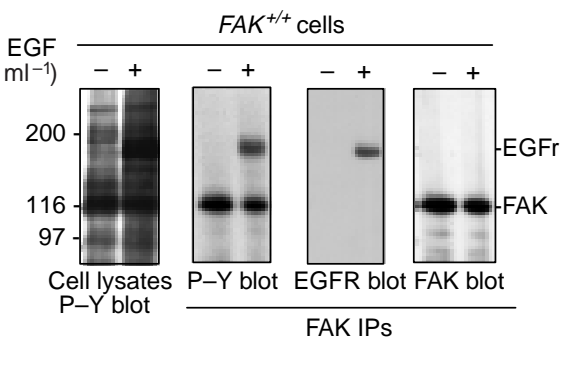

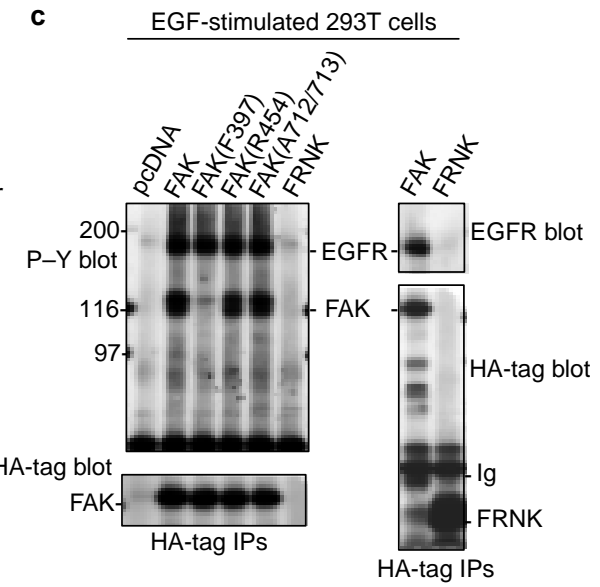

Figure 3 FAK forms a complex with the activated EGFR and is required for EGF-stimulated cell motility. a, In a chemotaxis assay using a modified Boyden chamber, $\mathrm{FAK}^{+/+}$fibroblasts and DA2 cells migrate towards EGF, whereas $F A K^{-1-}$ cells do not migrate. Values are menas \pm s.d. of at least three separate experiments. Starved $\mathrm{FAK}^{-1-}$ fibroblasts respond to EGF stimulation with enhanced tyrosine phosphorylation, as detected by anti-phosphotyrosine (P-Y) blotting of cell lysates. Numbers in the right panel represent $M_{r}$ in thousands. $\mathbf{b}$, Association of EGFR and endogenous FAK upon stimulation with EGF of $\mathrm{FAK}^{+/+}$cells, as detected by coimmunoprecipitation (IP) analyses with antibodies to FAK. c, Transfection of FAK constructs into 293T cells shows that the kinase activity of FAK, tyrosine phosphorylation, and the integrity of the FAK Y397 site are not required to mediate EGFR association in EGF-stimulated 293T cells. No EGFR association with the FAK Cterminal domain (FRNK) was detected. Ig, immunoglobulin.
Expression of the PDGFR in 293T cells led to growth-factorindependent phosphorylation of the PDGFR (Fig. 1c, lanes 1, 5). In the absence of HA-FAK expression, antibodies to the HA tag did not co-immunoprecipitate PDGFR after PDGF-BB stimulation (Fig. 1c, lanes 1, 2). In cells not transfected with PDGFR (Fig. 1c, lanes 3, 4), HA-tag antibodies did not co-immunoprecipitate with either a phosphotyrosine-containing protein of $\mathrm{M}_{\mathrm{r}} \sim 200 \mathrm{~K}$ (data not shown) or a PDGFR-immunoreactive band. However, upon coexpression of PDGFR and HA-FAK, antibodies to the HA tag weakly pulled down the PDGFR in the absence of growth factor, whereas strong PDGFR association with HA-FAK was detected after PDGF-BB stimulation of the 293T cells (Fig. 1c, lanes 5, 6). These results indicate that PDGF-BB stimulation may promote the recruitment of FAK into an active PDGFR signalling complex.

FAK Y397 phosphorylation is required for both integrin- and PDGF-stimulated cell motility. FAK mutants lacking the autophosphorylation/SH2-binding site (FAK(F397)), kinase activity (FAK(R454)), or the primary p130 ${ }^{\text {Cas }} \mathrm{SH} 3$-binding site (FAK(A712/ 713)) are ineffective in promoting fibronectin-stimulated cell migration when transiently expressed in $F_{A K}^{-/}$cells $^{15}$. These data indicate that several protein-protein interactions involving FAK may be necessary to promote integrin-initiated cell motility (haptotaxis). To determine whether similar interactions with FAK are required to support PDGF-stimulated cell motility (chemotaxis), we transiently transfected $F A K^{-/-}$cells with various FAK constructs and tested them for migration in response to PDGF-BB (Fig. 2a). Expression of HA-tagged FAK, FAK(R454), FAK(A712/713) or a Grb2-binding-site mutant (FAK(F925)) promoted a roughly eightfold increase in PDGF-stimulated cell migration, whereas equivalent expression of FAK(F397) did not effectively restore PDGFstimulated cell motility (Fig. 2a). All of the FAK mutants except FAK(F397) were tyrosine-phosphorylated in PDGF-stimulated $F A K^{-1-}$ cells (data not shown).

PDGF stimulates the association of Src-family PTKs with FAK. The one common functional site in FAK needed to promote both fibronectin- and PDGF-BB-stimulated cell migration is the autophosphorylation/SH2-binding site, Y397. As the kinase activity of FAK is not required for PDGF-stimulated cell migration, it is possible that other PTKs may transphosphorylate FAK at the Y397 site after PDGF stimulation of cells. To evaluate the potential contribu- tion of other FAK-associated kinases, we analysed HA-FAK immunoprecipitates from starved or PDGF-BB-stimulated DA2 cells for in vitro kinase activity using poly-Glu-Tyr as a substrate (Fig. 2b). In PDGF-BB-stimulated ( $\left.10 \mathrm{ng} \mathrm{ml}^{-1}, 5 \mathrm{~min}\right) \mathrm{DA} 2$ cells, poly-GluTyr transphosphorylation was increased sevenfold relative to serum-starved cells (Fig. 2b). Surprisingly, in parallel autophosphorylation assays, this increase in the PDGF-stimulated kinase activity of FAK was not reflected by strong PDGFR or FAK autophosphorylation activity in the HA-FAK immunoprecipitates, but was correlated with the recruitment of active Src-family PTKs to the activated FAK complex (Fig. 2b). A similar FAK-Src-PTK complex occurred after the addition of low concentrations of PDGF $\left(1-10 \mathrm{ng} \mathrm{ml}^{-1}\right)$ to Swiss $3 \mathrm{~T} 3$ cells $^{23}$.

SH2-mediated binding of Src-family proteins to the FAK Y397 site is competed by several other $\mathrm{SH} 2$-containing signalling proteins, such as $\mathrm{Shc}^{24}$, the $\mathrm{p} 85$ subunit of phosphatidylinositol-3-OH kinase $^{25}$, SHP-2 (ref. 26), phospholipase C- $\gamma 1$ (ref. 27) and Grb7 (ref. 28). To determine the importance of Src-family PTK activity in PDGF-stimulated migration of DA2 cells, we specifically inhibited Src kinase activity by transiently transfecting DA2 cells with an expression vector for C-terminal Src kinase $\left(\mathrm{p} 50^{\mathrm{Csk}}\right)$. Overexpression of $550^{\mathrm{Csk}}$ markedly inhibited PDGF-stimulated $\left(5 \mathrm{ng} \mathrm{ml}^{-1}\right)$ motility, whereas overexpression of the kinase-inactive mutant p50 $0^{\mathrm{Csk}}(\mathrm{K} 222 \mathrm{M})$ did not (Fig. 2c). These results indicate that active binding of Src-family PTKs to the FAK Y397 site may be the first of several important signalling events necessary to promote PDGFstimulated cell migration.

FAK function is required for EGF-stimulated cell migration. To test whether the role of FAK in promoting cell migration is growth-factor-specific, we carried out chemotaxis assays of $F A K^{+/+}, F A K^{-/}$and DA2 cells in a modified Boyden chamber using low concentrations of EGF (Fig. 3a). Whereas $F A K^{-/}$and DA2 cells expressed equivalent levels of EGFR (see Supplementary Information), $F A K^{-/}$cells were not capable of initiating a migratory response, even though enhanced tyrosine phosphorylation of EGFR and its downstream targets, such as Shc, readily occurred in EGF-stimulated $\left(10 \mathrm{ng} \mathrm{ml}^{-1}\right.$, $5 \mathrm{~min}$ ) $\mathrm{FAK}^{-/-}$cells (Fig. 3a). Similar to the stimulated formation of a complex containing activated PDGFR and FAK, the association of endogenous FAK with activated EGFR was detected by co-immunoprecipitation with anti-FAK antibody only after cells were stimu- 

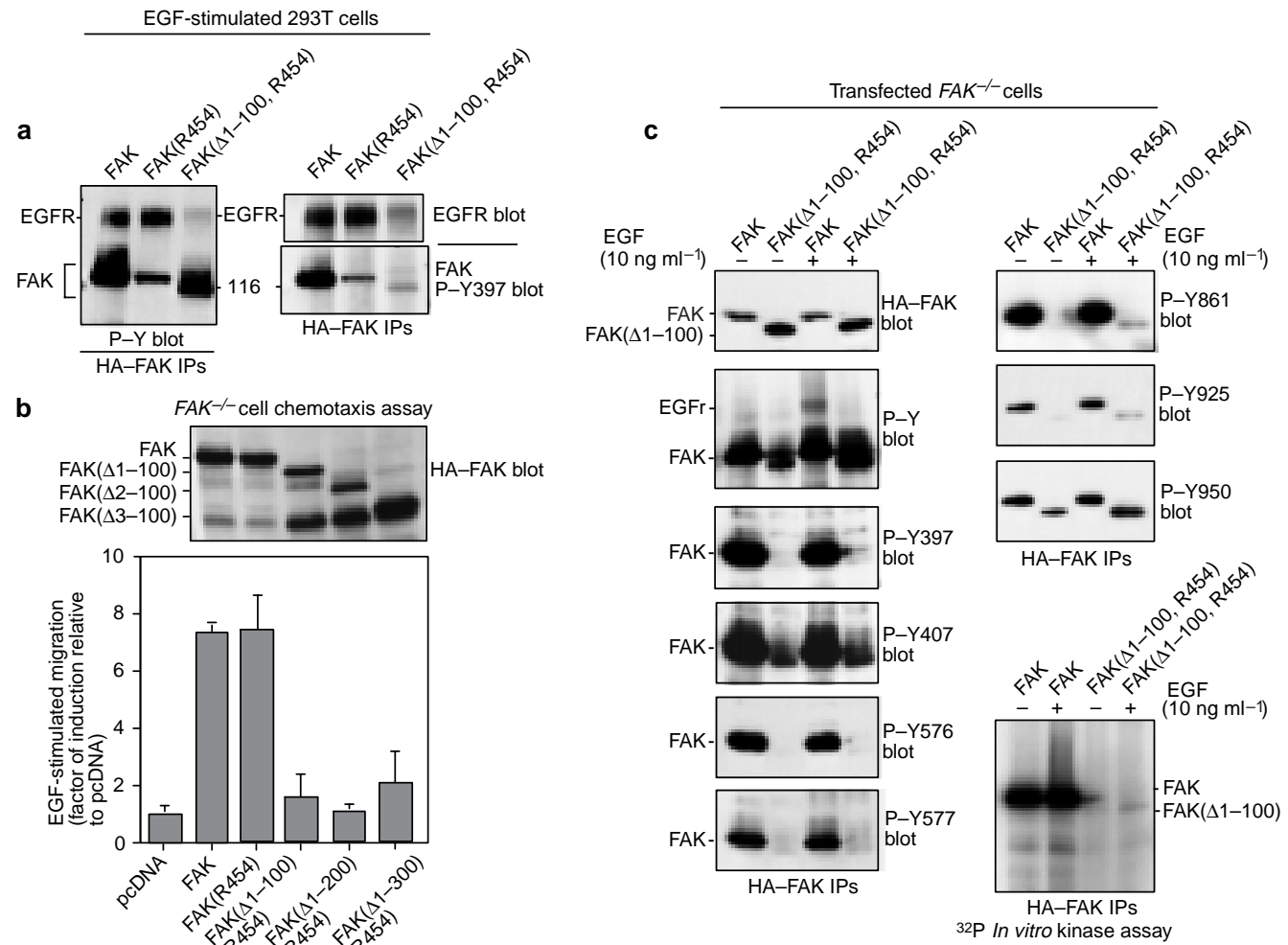

Figure 4 The FAK $\mathrm{N}$-terminal domain is required for association with EGFR and EGF-stimulated cell motility. a, Wild-type FAK and kinase-inactive FAK(R454), but not FAK( $\Delta 1-100$, R454), associate with activated EGFR in 293T cells. FAK(R454) is tyrosine phosphorylated at the $\mathrm{Y} 397$ site after EGF stimulation, whereas FAK( $\Delta 1-100$, R454) is only minimally tyrosine phosphorylated at this site. IPs, immunoprecipitates. Number between the two panels represents $M_{r}$ in thousands. $\mathbf{b}$, Upper panel, blotting for HA-tagged truncated versions of FAK. Lower panel, wild-type FAK and FAK(R454)

lated with EGF (Fig. 3b). In a further analogy with the PDGF results, co-immunoprecipitation anlayses showed no detectable association of Pyk2 with an activated EGFR complex after EGF stimulation of $F A K^{-/}$cells (data not shown).

FAK forms a complex with activated EGFR. To investigate further the association of FAK and EGFR, we transiently transfected 293T cells with various FAK mutant constructs and evaluated their association with endogenous EGFR using co-immunoprecipitation analyses after EGF stimulation (10 $\mathrm{ng} \mathrm{ml}^{-1}, 5 \mathrm{~min}$; Fig. $\left.3 \mathrm{c}\right)$. All the FAK mutants used, except the isolated FAK C-terminal domain (FRNK), formed complexes with activated EGFR (Fig. 3c). The fact that FAK(F397) readily formed a complex with activated EGFR, and yet showed only minimal levels of tyrosine phosphorylation, indicates that SH2-mediated binding of an adaptor protein to the FAK Y397 site may not be crucial to the FAK-EGFR interaction. By analogy with the results obtained from PDGF-stimulated $F A K^{--}$ cells (Fig. 2a), transient expression of FAK(F397) did not significantly enhance EGF-stimulated $F A K^{-/}$cell motility (data not shown). It has also been shown that inducible expression of $\mathrm{FAK}(\mathrm{F} 397)$ in $\mathrm{FAK}^{-/}$cells inhibits serum-stimulated migration ${ }^{16}$. Together, these results support the hypothesis that FAK(F397) fails to promote both integrin- ${ }^{15}$ and growth-factor-stimulated cell motility because it fails to form a productive signalling complex with downstream targets such as the Src-family PTKs.

The FAK N-terminal domain is required for EGF-stimulated motility. As the isolated FAK C-terminal domain did not detectably associate with activated EGFR in 293T cells (Fig. 3c), we investigated the possibility that the FAK-EGFR association is mediated by promote EGF-stimulated migration of $F A K^{-/}$cells equally, whereas $F A K(\triangle 1-100$, R454), FAK( $\Delta 1-200, R 454)$ and FAK( $\Delta 1-300, R 454)$ do not function to promote EGFstimulated migration. Values are means \pm s.d. of at least three separate experiments. c, FAK is phosphorylated at several sites and exhibits a high level of in vitro kinase activity when transiently expressed in $F A K^{-1}$ cells. Wild-type FAK, but not FAK $(\Delta 1-100$, R454), associates with activated EGFR in $F A K^{-/-}$cells. Phosphorylation of FAK( $\triangle 1-$ $100, \mathrm{R} 454)$ at the $Y 407$ and $Y 950$ sites is enhanced by EGF stimulation. the FAK N-terminal domain. Previous studies have shown that truncations of the FAK N-terminal domain lead to a greatly raised level of FAK tyrosine phosphorylation ${ }^{10}$. We therefore introduced a kinase-inactive mutation (R454) into a truncated version of FAK to form $\operatorname{FAK}(\Delta 1-100, \mathrm{R} 454)$. We expressed wild-type FAK, FAK $(\mathrm{R} 454)$ and FAK $(\Delta 1-100, \mathrm{R} 454)$ in $293 \mathrm{~T}$ cells and examined their ability to co-immunoprecipitate with activated EGFR after EGF stimulation (10 $\mathrm{ng} \mathrm{ml}^{-1}, 5 \mathrm{~min}$; Fig. 4a). Whereas FAK(R454) was strongly associated with EGFR and also weakly tyrosine phosphorylated, FAK $(\Delta 1-100, \mathrm{R} 454)$, although tyrosine phosphorylated, did not detectably associate with activated EGFR (Fig. 4a). Wild-type FAK and FAK(R454) were phosphorylated at the Y397 site, as detected by antibodies specific to phosphorylated Y397, whereas $\mathrm{FAK}(\Delta 1-100, \mathrm{R} 454)$ was only minimally phosphorylated at this site (Fig. 4a). These results indicate that the integrity of the FAK N-terminal domain may be important for mediating interactions with activated EGFR.

To test the functional correlation between the FAK-EGFR association and EGF-stimulated cell migration, we transiently expressed mutant or truncated FAK constructs in $F A K^{--}$cells and assessed their ability to promote migration after EGF stimulation $\left(5 \mathrm{ng} \mathrm{m}^{-1}\right.$; Fig. 4b). Expression of either wild-type FAK or FAK(R454) promoted migration of $F A K^{-1-}$ cells equally well, whereas $\mathrm{FAK}(\Delta 1-100$, R454), FAK $(\Delta 1-200, \mathrm{R} 454)$ and FAK $(\Delta 1-300, \mathrm{R} 454)$ did not significantly promote cell migration above control levels (Fig. $4 \mathrm{~b})$. Transfection of kinase-active $\operatorname{FAK}(\Delta 1-100)$ also failed to promote EGFstimulated migration of $F A K^{--}$cells (data not shown), but its transient expression significantly reduced $F A K^{-1-}$ cell adhesion, which 

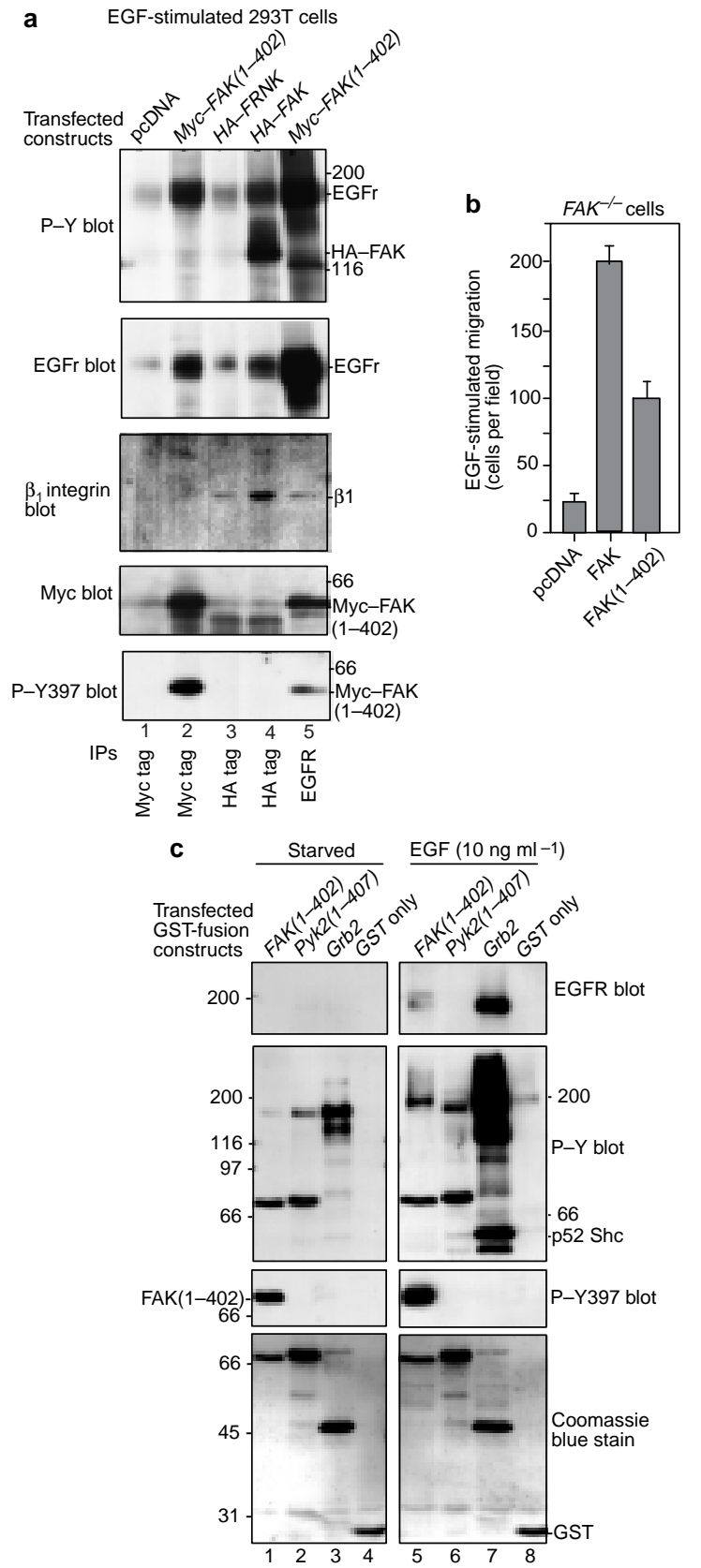

Figure 5 Exogenously expressed FAK N-terminal domain can form a complex with activated EGFR. a, 293T cells were transfected with the indicated constructs and stimulated with EGF. Sequential blotting of Myctag, HA-tag, or EGFR immunoprecipitates (IPs) shows that the Myc-tagged FAK N-terminal domain (Myc-FAK(1-402); $M_{\mathrm{r}} \sim 60 \mathrm{~K}$ ) associates with EGFR. Wild-type FAK and the FAK C-terminal domain (FRNK), but not FAK(1-402), form a complex with $\beta_{1}$ integrins. FAK(1-402) is transphosphorylated at the Y397 site in EGF-stimulated cells. Numbers represent $M_{r}$ in thousands. $\mathbf{b}$, FAK(1-402) promotes EGF-stimulated migration of $\mathrm{FAK}^{-1-}$ cells half as well as untruncated FAK. Values are means \pm s.d. of two separate experiments. c, Expression of GST-FAK(1-402), but not GST-Pyk2(1-407), leads to the formation of a complex with activated EGFR in vivo upon EGF stimulation of 293T cells. Direct binding of GST-Grb2 to EGFR is much stronger than GSTFAK(1-402) association. Both GST-FAK(1-402) and GST-Pyk2(1-407) are tyrosine phosphorylated. GST-FAK(1-402) phosphorylation at the Y397 site is enhanced after EGF stimulation. Staining of the membrane with Coomassie blue shows the amounts of GST constructs associated with glutathione beads. hampered conclusions from motility assays. Nevertheless, the results obtained from FAK-truncation mutants show that formation of the FAK-EGFR complex is correlated to the promotion of EGF-stimulated cell motility. By analogy with PDGF-stimulated motility (Fig. 2a), the kinase activity of FAK was not required for EGF-stimulated cell migration. This can be explained mechanistically by the fact that FAK may be a substrate for other PTKs upon EGF stimulation of cells. This idea is supported by our finding that untruncated FAK(R454) associated with activated EGFR and was phosphorylated at the Y397/SH2-binding site when expressed in 293 T cells (Fig. 4a).

To investigate further the transphosphorylation of FAK after EGF stimulation and to determine whether $\operatorname{FAK}(\Delta 1-100, \mathrm{R} 454)$ is phosphorylated at the Y397 site when transiently expressed in $F A K^{-/-}$cells, we sequentially analysed immunoprecipitates of HA-tagged FAK and $\operatorname{FAK}(\Delta 1-100, \mathrm{R} 454)$, using phosphospecific antibodies that recognize different FAK phosphorylation sites (Fig. 4c). Under both starved and EGF-stimulated conditions, HA-FAK was highly tyrosine phosphorylated at the Y397, Y407, Y576, Y577 and Y861 sites, and weakly phosphorylated at the Y925 and Y950 sites. HA-FAK transiently expressed in $F A K^{-/-}$cells associated with EGFR after EGF stimulation, yet it exhibited a high level of in vitro kinase activity under both starved and EGF-stimulated conditions (Fig. 4c). Association of FAK $(\Delta 1-100, \mathrm{R} 454)$ with EGFR was not detected in $F A K^{-1-}$ cells, although the total level of tyrosine phosphorylation of $\operatorname{FAK}(\Delta 1-100, \mathrm{R} 454)$ markedly increased after EGF stimulation (Fig. 4c). Using the phosphospecific FAK antibodies, we detected $\mathrm{FAK}(\Delta 1-100, \mathrm{R} 454)$ phosphorylation at the Y407 and Y950 sites, but no significant phosphorylation at the $\mathrm{Y} 397$ site or in the kinase domain at Y576 and Y577 (Fig. 4c). The mechanism of tyrosine phopshorylation of $\operatorname{FAK}(\Delta 1-100, \mathrm{R} 454)$ is unknown. However, the fact that FAK $(\Delta 1-100, \mathrm{R} 454)$ does not detectably associate with activated EGFR and is not phosphorylated at the Y397 site supports our previous conclusions that these two events are important for FAK function in promoting EGF-stimulated motility.

The isolated FAK N-terminal domain can associate with activated EGFR. To determine whether the FAK-EGFR interaction can occur in the absence of the focal-adhesion-targeting signals located in the FAK C-terminal domain, we expressed FAK residues 1-402 (FAK $(1-402)$ ) as a Myc-epitope-tagged protein in 293T cells. Immunoprecipitation and blotting against the Myc tag detected a protein of $M_{\mathrm{r}} \sim 60 \mathrm{~K}$ in cells transfected with this construct (Fig. 5a, lane 2). Co-immunoprecipitation analyses showed that Myc-tagged FAK(1-402) and HA-tagged FAK associated with activated EGFR (Fig. 5a, lanes 2, 4), whereas HA-tagged FRNK did not show a strong or reproducible association (Fig. 5a, lane 3 and Fig. 3c). Analysis of association of $\beta_{1}$ integrin with the FAK constructs used showed that it was present in both the FRNK and the FAK immunoprecipitates but not in those of Myc-tagged FAK(1-402) (Fig. 5a, lanes 2-4). This result indicates that the association of the FAK Nterminal domain with EGFR may not involve linkages through $\beta_{1}$ integrins; in this respect our results are not consistent with a previous report of in vitro binding of $\beta_{1}$ integrin peptides to the FAK Nterminal domain ${ }^{29}$.

To confirm the association of the FAK N-terminal domain with EGFR, we carried out reciprocal co-immunoprecipitation experiments using anti-EGFR antibodies, and blotted the immunoprecipitates for associated Myc-tagged proteins (Fig. 5a, lane 5). Myctagged FAK(1-402) was phosphorylated at the Y397/SH2-binding site after EGF stimulation of $293 \mathrm{~T}$ cells, which is indicative of a transphosphorylation event (Fig. 5a, lanes 2, 5). A low level of $\beta_{1}$ integrin-subunit signal was also detected in the EGFR immunoprecipitate (Fig. 5a, lane 5), which is consistent with previous reports of EGFR and integrin co-clustering ${ }^{2}$. FAK(1-402) expressed in $F A K^{--}$cells promoted cell migration in response to EGF at half the level stimulated by wild-type FAK (Fig. 5b). These results support the idea that although FAK(1-402) forms a complex with activated EGFR and is phosphorylated at the Y397 site, 

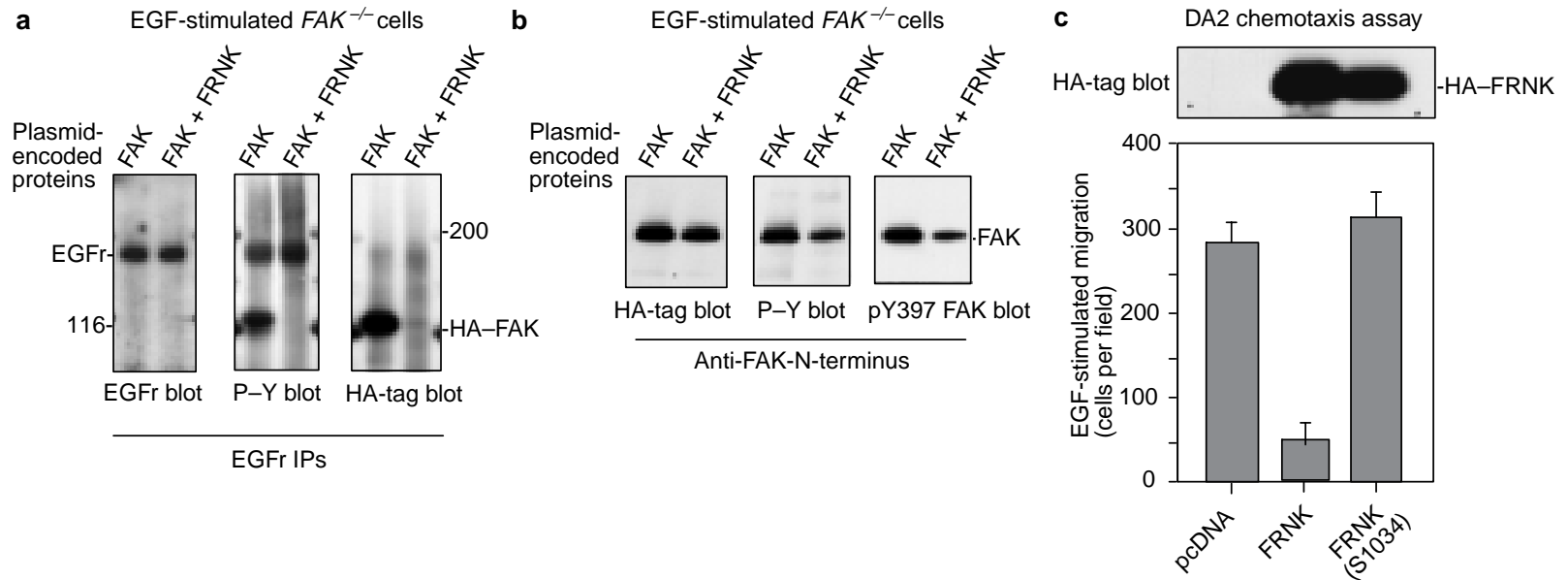

Figure 6 Expression of the FAK C-terminal domain inhibits the FAK-EGFR association and EGF-stimulated cell motility. a, Co-expression of the FAK Cterminal domain (FRNK) with untruncated FAK in EGF-stimulated $\mathrm{FAK}^{--}$cells inhibits FAK association with activated EGFR complexes. IPs, immunoprecipitates.

Numbers represent $M_{r}$ in thousands. $\mathbf{b}$, Co-expression of FRNK with untruncated
FAK in EGF-stimulated FAK-1- cells suppresses FAK phosphorylation at the Y397 site. c, Expression of FRNK, but not the point mutant FRNK(S1034) that does not localize to focal contact sites, inhibits EGF-stimulated DA2 cell motility, as measured by a modified Boyden-chamber assay. Values are means \pm s.d. of at least three separate experiments.

Expression of the FAK C-terminal domain inhibits EGF-stimulated cell motility. Interactions, mediated by the C-terminal domain, of FAK with proteins such as paxillin ${ }^{7,8}$ and talin ${ }^{9}$ function to promote the targeting to, and the indirect association of, FAK with integrins at focal-contact sites. As expression and tyrosine phosphorylation of FAK(1-402) did not promote EGF-stimulated migration of $\mathrm{FAK}^{-/}$cells to the same extent as with wild-type FAK (Fig. 5b), full activity may require C-terminal-domain-mediated targeting of FAK to focal contact sites. As C-terminal truncations of

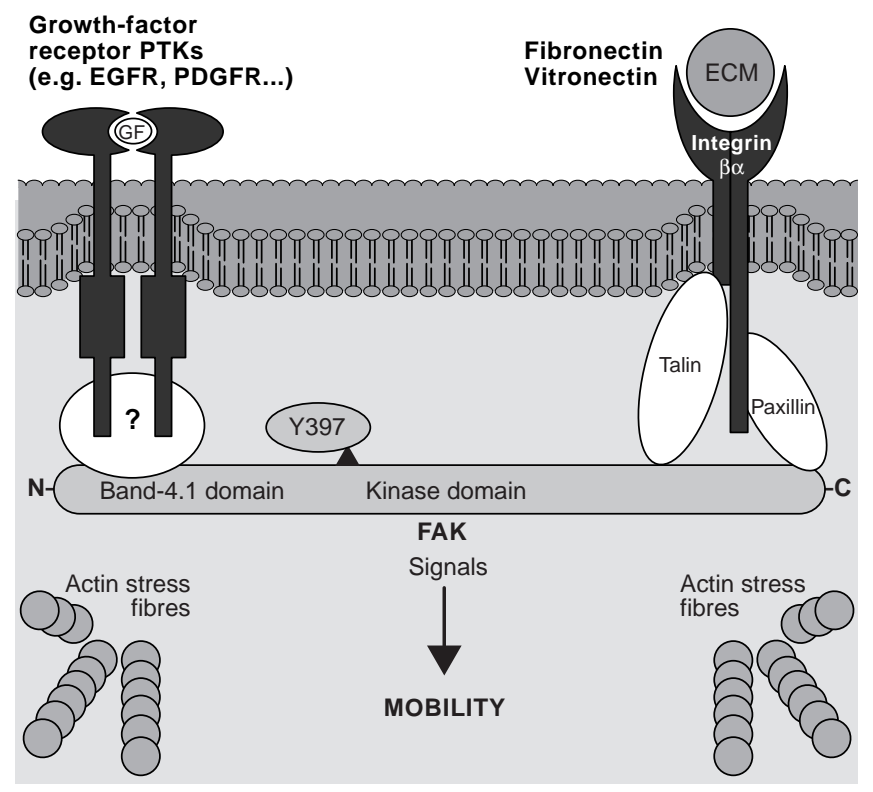

Figure 7 Model of FAK function. Indirect localization of FAK to sites of integrin and growth-factor-receptor clustering places FAK in a position to act as a receptorproximal regulatory protein. Phosphorylation of FAK at the Y397 site and the integrity of the actin cytoskeleton are both required for FAK function in promoting both growth-factor (GF)- and integrin-mediated cell motility. 
FAK were subject to proteolytic degradation when expressed in $F A K^{--}$cells (data not shown), we exogenously expressed the FAK Cterminal domain (FRNK) as a competitive inhibitor of FAK localization to sites of integrin-receptor clustering ${ }^{32}$.

Although FRNK did not strongly associate with the activated EGFR complex when expressed in 293T cells (Fig. 3d), co-expression of FRNK with FAK in $F A K^{-/}$cells disrupted the association of FAK with the activated EGFR complex (Fig. 6a) and suppressed EGF-stimulated FAK phosphorylation at the Y397 site (Fig. 6b). Significantly, FRNK expression potently inhibited EGF-stimulated migration of DA2 cells (Fig. 6c), whereas equivalent expression of a FRNK point mutant (FRNK(S1034)) that does not strongly localize to focal-contact sites ${ }^{15}$ did not inhibit DA2 motility (Fig. 6c) or disrupt the stimulated formation of a FAK-EGFR complex (data not shown). These results support the conclusion that full FAK function in promoting EGF-stimulated motility involves a combination of distinct interactions mediated by both the $\mathrm{N}$ and the $\mathrm{C}$ termini (Fig. 7). In addition, the results obtained from FRNK overexpression indicate that a link between the FAK $\mathrm{N}$ terminus and EGFR may be facilitated and/or stabilized by interactions between the FAK C terminus and integrins.

\section{Discussion}

It is well documented that FAK has important functions in integrininitiated signalling events. Changes in the tyrosine-phosphorylation status of FAK also occur after stimulation with soluble growth factor in several different cell types. We have shown here that FAK is important in linking PDGFR and EGFR activation to the cellular machinery that promotes directed cell migration. Our results support a new function for the unique FAK N-terminal domain which, upon exogenous expression, associated with an activated EGFR complex. The binding of the FAK N-terminal domain to EGFR was not as strong as direct Grb2 SH2-domain-mediated binding to the phosphorylated EGFR. In addition, the association of FAK with activated complexes of both EGFR and PDGFR could be disrupted by pretreatment of cells with cytochalasin $\mathrm{D}$, which prevents actin polymerization but does not block tyrosine phosphorylation of PDGFR or EGFR. As we could not detect a direct association between the FAK N-terminal domain and EGFR in farwestern analyses, this interaction, like the co-localization of FAK with integrin receptors, may be mediated by one or more intermediary bridging proteins.

The overall significance of our biochemical findings is highlighted by the fact that FAK is recruited to sites of growth-factorreceptor and integrin clustering in intact cells (see Supplementary Information) and that FAK expression is required for both PDGFand EGF-stimulated cell motility. This places FAK in a critical position as a receptor-proximal component of both integrin- and growth-factor-receptor PTK signalling pathways (Fig. 7). We found that deletions of the FAK N-terminal domain disrupted the association of FAK with an activated EGFR complex. FAK constructs lacking an intact N-terminal domain did not promote EGF-stimulated motility when analysed in gain-of-function chemotaxis assays using $F A K^{-1-}$ cells. However, tyrosine phosphorylation of FAK and exogenous expression of its $\mathrm{N}$-terminal domain only partially functioned to promote EGF-stimulated $F A K^{-/-}$cell motility. These results indicate that localization of FAK to sites of integrin-receptor clustering is also important for cell motility. Indeed, overexpression of the FAK C-terminal domain acted to disrupt the association of FAK with activated EGFR complexes, promote FAK dephosphorylation at the Y397 site and inhibit EGF-stimulated cell motility. Thus, FAK connections to both growth-factor receptors and integrins are required to coordinate cell migration.

The association of FAK with an activated CCR5 receptor complex has recently been demonstrated using co-immunoprecipitation analyses ${ }^{33}$. In addition, FAK has been shown to associate with the inactive EphA2 $\mathrm{PTK}^{34}$. Although these reports did not elucidate the molecular mechanisms mediating these FAK-receptor interac- tions, we speculate that the involvement of FAK with other transmembrane-receptor signalling pathways may be reflected by the fact that tyrosine phosphorylation of FAK can be modulated by several different extracellular stimuli (reviewed in ref. 11). Specificity between FAK- and Pyk2-mediated signalling events may be determined by differences in the interactions undertaken by their respective N-terminal domains.

With respect to the mechanism of FAK function in cell motility, we found, surprisingly, that the kinase activity of FAK was not required to promote either PDGF- or EGF-stimulated cell migration in $F^{-/-}$cells, even though the same cells require FAK's kinase activity to promote fibronectin-stimulated cell motility ${ }^{15}$. Direct binding of $\mathrm{p} 130^{\mathrm{Cas}}$ to FAK was also not required for PDGF-stimulated cell migration, although previous analyses have shown that FAK-p130 Cas interactions are important for fibronectin- and integrin-stimulated haptotaxis ${ }^{15,17}$. These results indicate that the molecular mechanisms of FAK-mediated motility differ depending upon whether the primary cell stimulus is initiated by the activation of integrin or growth-factor receptors. Mechanistically, the requirement for FAK's kinase activity in promoting integrin-stimulated motility can be explained by the fact that integrins lack intrinsic catalytic activity. For growth-factor-stimulated motility, FAK phosphorylation may be initiated by receptor-PTK activation. We found that untruncated kinase-inactive FAK and the FAK N-terminal domain were transphosphorylated at the Y397 site after EGF stimulation, an indication that other PTKs participate in FAK-mediated signalling events.

A common and important mechanistic connection needed to promote both integrin- and growth-factor-stimulated cell migration was the FAK Y397 site. Phosphorylation at this site creates an SH2-binding site for a number of different signalling and adaptor proteins. Our results show that PDGF stimulation promotes the recruitment of active Src-family PTKs to FAK, and that inhibition of Src-family PTK activity by overexpression of $\mathrm{p} 50^{\mathrm{Csk}}$ prevents PDGF- and FAK-mediated migration. As $F A K^{-/}$cells exhibit an overabundance of focal contacts and decreased cell motility, our results also support a working model for FAK function in promoting focal-contact turnover. The catalytic activity of Src-family PTKs has been shown to promote the turnover of focal-contact structures during cell motility ${ }^{35}$, and Src-FAK interactions are important for EGF-stimulated cell migration ${ }^{36}$. Therefore, FAK-mediated localization of active Src-family PTKs to sites of growth-factor- and integrin-receptor clustering may initiate focal-contact remodelling and migratory signals.

In summary, our results show that FAK can function as an important receptor-proximal component to promote cell migration. As FAK is overexpressed in a variety of invasive human tumours $^{37,38}$ and the $F A K$ gene is amplified in a variety of human cancer cells $^{39}$, strategies to reduce levels of FAK protein or phosphorylation at the Y397/SH2-binding site may provide a way to interfere with enhanced growth-factor- and integrin-stimulated cell motility in both vascular and neoplastic diseases.

\section{Methods \\ Cell culture. \\ $F A K^{+/+}, F A K^{-/}$and DA2 fibroblasts were cultured, serum starved and transfected as described ${ }^{15}$. $F A K^{+/+}$, $F A K^{--}$and DA2 cells have the same $p 53^{--}$genetic background. Human $293 \mathrm{~T}$ cells were cultured and transfected as described ${ }^{40}$}

\section{DNA constructs.}

HA-tagged constructs for wild-type FAK, FAK(F397), FAK(R454), FAK(A712/713), FAK(F925), FRNK and FRNK(S1034) were used as described ${ }^{15}$. Expression vectors for $\mathrm{p} 50^{\mathrm{csk}}$ and $\mathrm{p} 50^{\mathrm{csk}}(\mathrm{K} 222 \mathrm{M})$ were used as described ${ }^{14}$. FAK $(\Delta 1-100)($ ref. 40$)$ was cloned into FAK(R454) as a KpnI/ClaI fragment. MycFAK(1-402) was created by ligating a BamHI/ClaI wild-type FAK fragment into the BglII/XbaI sites of pCS-Myc ${ }^{14}$ using the primers 5'-CGATGGTGGTTGAT and 5'-CTAGATCAACCACCAT as linkers. $\mathrm{BamHI} / \mathrm{ClaI}$-ended fragments containing the nucleotide sequence encoding FAK $(\Delta 1-200)$ and $\mathrm{FAK}(\Delta \mathrm{l}-300)$ were created using the polymerase chain reaction (PCR) and cloned into the same sites in pcDNA encoding FAK(R454). PCR was used to create a BamHI/XhoI-ended fragment containing the nucleotide sequence encoding FAK(1-402), FAK(1-402, $\Delta 1-100)$, Pyk 2(1-407) and human Grb2. The 3 '-flanking PCR primer contained the nucleotide sequence encoding a protein kinase A consensus 
phosphorylation site (amino-acid sequence RRASVG) upstream of the XhoI site in all constructs. Constructs were cloned into the BamHI/XhoI sites of pGEX-4T and subcloned as BamHI/NotI fragments into pEBG mammalian GST-fusion expression vector. All DNA constructs created by PCR were verified by sequencing.

\section{Chemotaxis.}

For modified Boyden-chamber (Millipore, Bedford, MA) motility assays, both sides of membranes wer coated with rat-tail collagen $\left(5 \mu \mathrm{gml}^{-1}\right.$ in PBS; Boehringer) for $2 \mathrm{~h}$ at $37^{\circ} \mathrm{C}$ and washed with PBS; chambers were placed in 24-well dishes containing migration media $(0.4 \mathrm{ml}$ DMEM containing $0.5 \%$ BSA) with or without human recombinant PDGF-BB or EGF (Calbiochem) at the indicated concentrations. For transient-transfection cell-migration assays, $2.5 \mu \mathrm{g} \mathrm{pcDNA3-lac} Z$ were combined with $2.5 \mu \mathrm{g}$ FAK expression plasmids to identify transfected cells. Serum-starved cells $\left(1 \times 10^{5}\right.$ cells in 0.3 $\mathrm{ml}$ migration media) were added to the upper compartment and, after $3 \mathrm{~h}$ at $37^{\circ} \mathrm{C}$, cells on the membrane upper surface were removed with a cotton-tip applicator; migratory cells on the lower membrane surface were fixed by treatment with methanol and acid and then either stained $(0.1 \%$ crystal violet, $0.1 \mathrm{M}$ borate $\mathrm{pH} 9.0$ and $2 \%$ ethanol) or analysed for transfected $\beta$-galactosidase activity using X-gal as a substrate. Cell-migration values were determined either by dye elution and absorbence measurements at $600 \mathrm{~nm}$ or by counting $\beta$-gal-stained cells (measured as cells per field using a $\times 40$ objective). Means were taken from three individual chambers. Background levels of cell migration (less than $5 \%$ of total) in the absence of chemotaxis stimuli ( $0.5 \%$ BSA only) were subtracted from all points.

\section{Immunoprecipitation.}

Cells on $10-\mathrm{cm}$ plates were lysed with $0.5 \mathrm{ml}$ modified RIPA lysis buffer ${ }^{15}$; lysates were immediately diluted with $0.5 \mathrm{ml}$ HNTG buffer (50mM HEPES pH 7.4, $150 \mathrm{mM} \mathrm{NaCl}, 0.1 \%$ Triton X-100 and $10 \%$ glycerol), incubated with agarose beads and cleared by centrifugation. Immunoprecipitates with the indicated antibodies were carried out for $4 \mathrm{~h}$ at $4{ }^{\circ} \mathrm{C}$ and collected on agarose beads with protein $\mathrm{A}$ (Repligen, Cambridge, MA) or protein G-plus (Calbiochem); the precipitated protein complexes were washed at $4^{\circ} \mathrm{C}$ in Triton-only lysis buffer (modified RIPA without sodium deoxycholate and SDS) and then in HNTG buffer before direct analysis by SDS-PAGE. For GST-fusion proteins, lysates of $293 \mathrm{~T}$ cells were precleared and incubated with $20 \mu \mathrm{l}$ glutathione-agarose-bead slurry (Sigma) for $2 \mathrm{~h}$ at $4{ }^{\circ} \mathrm{C}$. Beads were pelleted by centrifugation and washed three times in $1 \%$ Triton buffer before direct analysis by SDS-PAGE. Associated GST-fusion proteins were observed by staining with Coomassie blue and immobilization on polyvinylidene fluoride membranes (PVDF; Millipore).

\section{In vitro kinase (IVK) assay.}

IVK assays of FAK immunoprecipitates in the presence or absence of poly-Glu-Tyr (4:1; Sigma) were carried out as described ${ }^{14}$

\section{Immunoblotting.}

Proteins analysed by SDS-PAGE were transferred to PVDF membranes, blocked in 2\% BSA and Trisbuffered saline with $0.05 \%$ Tween- 20 for $2 \mathrm{~h}$ at room temperature and then incubated with either $1 \mu \mathrm{g}$ $\mathrm{ml}^{-1}$ monoclonal antibody or a 1:1,000 dilution of polyclonal antibodies for $2 \mathrm{~h}$ at room temperature. Bound primary antibody was observed by enhanced chemiluminescence detection and subsequent reprobing of membranes was carried out as described ${ }^{15}$. Anti-phosphotyrosine and anti-PDGFR antibodies were from Upstate Biotechnology (Lake Placid, NY); anti-Myc- and anti-HA-tag antibodies were from Covance Research (Berkeley, CA); anti-EGFR and anti-Src antibodies were from Santa Cruz Negatively pre-adsorbed and affinity-purified polyclonal antibodies to peptides corresponding to the sequences surrounding FAK tyrosine-phosphorylation sites Y397, Y407, Y576, Y577, Y861, Y925 and Y950 were from BioSource International (Camarillo, California, USA). Affinity-purified polyclonal antibodies to FAK, Pyk2 and Csk were used as described ${ }^{14}$.

RECEIVED 7 OCTOBER 1999; REVISED 26 JANUARY 2000; ACCEPTED 10 MARCH 2000; PUBLISHED 27 MARCH 2000.

1. Schneller, M., Vuori, K. \& Ruoslahti, E. $\alpha \mathrm{v} \beta 3$ integrin associates with activated insulin and PDGF $\beta$ receptors and potentiates the biological activity of PDGF. EMBO J. 16, 5600-5607 (1997).

2. Miyamoto, S., Teremoto, H., Gutkind, J. S. \& Yamada, K. M. Integrins can collaborate with growth factors for phosphorylation of receptor tyrosine kinases and MAP kinase activation: roles of integrin aggregation and occupancy of receptors. J. Cell Biol. 135, 1633-1642 (1996).

3. Howe, A., Aplin, A. E., Alahari, S. K. \& Juliano, R. L. Integrin signaling and cell growth control. Curr. Opin. Cell Biol. 10, 220-231 (1998).

4. Giancotti, F. G. \& Ruoslahti, E. Integrin signaling. Science 285, 1028-1032 (1999).

5. Schwartz, M. A. \& Baron, V. Interactions between mitogenic stimuli, or, a thousand and one connections. Curr. Opin. Cell Biol. 11, 197-202 (1999).

6. Hildebrand, J. D., Schaller, M. D. \& Parsons, J. T. Identification of sequences required for the efficien localization of the focal adhesion kinase, pp125 $5^{\mathrm{FAK}}$, to cellular focal adhesions. J. Cell Biol. 123, 9931005 (1993).

7. Tachibana, K., Sato, T., D'Avirro, N. \& Morimoto, C. Direct association of $\mathrm{pp} 125^{\mathrm{FAK}}$ with paxillin, the focal adhesion-targeting mechanism of pp $125^{\mathrm{FAK}}$. J. Exp. Med. 182, 1089-1100 (1995).

8. Liu, S. et al. Binding of paxillin to alpha 4 integrins modifies integrin-dependent biological responses. Nature 402, 676-681 (1999).

9. Chen, H. C. et al. Interaction of focal adhesion kinase with cytoskeletal protein talin. J. Biol. Chem. 270, 16995-16999 (1995)

10. Schlaepfer, D. D. \& Hunter, T. Evidence for in vivo phosphorylation of the Grb 2 SH 2-domain binding site on focal adhesion kinase by Src-family protein-tyrosine kinases. Mol. Cell. Biol. 16, 5623 5633 (1996).

11. Schlaepfer, D. D., Hauck, C. R. \& Sieg, D. J. Signaling through focal adhesion kinase. Prog. Biophys. Mol. Biol. 71, 435-478 (1999).

12. Tamura, M. et al. Inhibition of cell migration, spreading, and focal adhesions by tumor suppressor
PTEN. Science 280, 1614-1617 (1998).

13. Gu, J. et al. Shc and FAK differentially regulate cell motility and directionality modulated by PTEN. J Cell Biol. 146, 389-404 (1999).

14. Sieg, D. J. et al. Pyk2 and Src-family protein-tyrosine kinases compensate for the loss of FAK in fibronectin-stimulated signaling events but Pyk2 does not fully function to enhance FAK cell migration. EMBO J. 17, 5933-5947 (1998).

15. Sieg, D. J., Hauck, C. R. \& Schlaepfer, D. D. Required role of focal adhesion kinase (FAK) for integrinstimulated cell migration. J. Cell Sci. 112, 2677-2691 (1999).

16. Owen, J. D., Ruest, P. J., Fry, D. W. \& Hanks, S. K. Induced focal adhesion kinase (FAK) expression in FAK-null cells enhances cell spreading and migration requiring both auto- and activation loop phosphorylation sites and inhibits adhesion-dependent tyrosine phosphorylation of Pyk 2. Mol. Cell Biol. 19, 4806-4818 (1999).

17. Cary, L. A., Han, D. C., Polte, T. R., Hanks, S. K. \& Guan, J.-L. Identification of p130 ${ }^{\mathrm{Cas}}$ as a mediator of focal adhesion kinase-promoted cell migration. J. Cell Biol. 140, 211-221 (1998)

18. Gilmore, A. P. \& Romer, L. H. Inhibition of focal adhesion kinase (FAK) signaling in focal adhesions decreases cell motility and proliferation. Mol. Biol. Cell 7, 1209-1224 (1996).

19. George, E. L., Georges-Labouesse, E. N., Patel-King, R. S., Rayburn, H. \& Hynes, R. O. Defects in mesoderm, neural tube and vascular development in mouse embryos lacking fibronectin. Development 119, 1079-1091 (1993).

20. Furuta, Y. et al. Mesodermal defect in late phase of gastrulation by a targeted mutation of focal adhesion kinase, FAK. Oncogene 11, 1989-1995 (1995).

21. Ilic, D. et al. Reduced cell motility and enhanced focal adhesion contact formation in cells from FAKdeficient mice. Nature 377, 539-544 (1995)

22. Chen, H. C. \& Guan, J. L. The association of focal adhesion kinase with a $200-\mathrm{kDa}$ protein that is tyrosine phosphorylated in response to platelet-derived growth factor. Eur. J. Biochem. 235, 495-500 (1996).

23. Salazar, E. P. \& Rozengurt, E. Bombesin and platelet-derived growth factor induce association of endogenous focal adhesion kinase with Src in intact Swiss 3T3 cells. J. Biol. Chem. 274, 28371-28378 (1999).

24. Schlaepfer, D. D., Jones, K. C. \& Hunter, T. Multiple Grb2-mediated integrin-stimulated signaling pathways to ERK 2/mitogen-activated protein kinase: Summation of both c-Src and FAK-initiated tyrosine phosphorylation events. Mol. Cell Biol. 18, 2571-2585 (1998).

25. Chen, H. C., Appeddu, P. A., Isoda, H. \& Guan, J. L. Phosphorylation of tyrosine 397 in focal adhesion kinase is required for binding phosphatidylinositol 3-kinase. J. Biol. Chem 271, 2632926334 (1996).

26. Manes, S. et al. Concerted activity of tyrosine phosphatase SHP-2 and focal adhesion kinase in regulation of cell motility. Mol. Cell Biol. 19, 3125-3135 (1999).

27. Zhang, X. et al. Focal adhesion kinase promotes phospholipase C-gamma 1 activity. Proc. Natl Acad. Sci. USA 96, 9021-9026 (1999).

28. Han, D. C. \& Guan, J. L. Association of focal adhesion kinase with grb7 and its role in cell migration. J. Biol. Chem. 274, 24425-24430 (1999).

29. Schaller, M. D., Otey, C. A., Hildebrand, J. D. \& Parsons, J. T. Focal adhesion kinase and paxillin bind peptides mimicking $\beta$ integrin cytoplasmic domains. J. Cell Biol. 130, 1181-1187 (1995).

30. Girault, J. A., Labesse, G., Mornon, J. P. \& Callebaut, I. The N-termini of FAK and JAKs contain divergent band 4.1 domains. Trends Biochem. Sci. 24, 54-57 (1999).

31. Lev, S. et al. Identification of a novel family of targets of PYK2 related to Drosophila retinal degeneration B (rdgB) protein. Mol. Cell. Biol. 19, 2278-2288 (1999).

32. Richardson, A. \& Parsons, J. T. A mechanism for regulation of the adhesion-associated protein tyrosine kinase pp $125^{\mathrm{FAK}}$. Nature 380, 538-540 (1996).

33. Cicala, C. et al. Induction of phosphorylation and intracellular association of CC chemokine receptor 5 and focal adhesion kinase in primary human CD4+ T cells by macrophage-tropic HIV envelope. J. Immunol. 163, 420-426 (1999).

34. Miao, H., Burnett, E., Kinch, M., Simon, E. \& Wang, B. Activation of EphA2 kinase suppresses integrin function and causes focal adhesion kinase dephosphorylation. Nature Cell Biol. 2, 62-69 (2000).

35. Fincham, V. J. \& Frame, M. C. The catalytic activity of Src is dispensable for translocation to focal adhesions but controls the turnover of these structures during cell motility. EMBO J. 17, 81-92 (1998).

36. Brunton, V. G., Ozanne, B. W., Paraskeva, C. \& Frame, M. C. A role for epidermal growth factor receptor, c-Src and focal adhesion kinase in an in vitro model for the progression of colon cancer. Oncogene 14, 283-293 (1997).

37. Owens, L. V.et al. Overexpression of the focal adhesion kinase (p125FAK) in invasive human tumors. Cancer Res. 55, 2752-2755 (1995).

38. Kornberg, L. J. Focal adhesion kinase and its potential involvement in tumor invasion and metastasis. Head Neck 20, 745-752 (1998).

39. Agochiya, M. et al. Increased dosage and amplification of the focal adhesion kinase gene in human cancer cells. Oncogene 18, 5646-5653 (1999).

40. Schlaepfer, D. D., Broome, M. A. \& Hunter, T. Fibronectin-stimulated signaling from a focal adhesion kinase- c-Src complex: involvement of the Grb 2, p130 ${ }^{\mathrm{cas}}$, and Nck adaptor proteins. Mol. Cell Biol. 17, 1702-1713 (1997)

\section{ACKNOWLEDGEMENTS}

We thank A. Moore and S. Reider for assistance, M. Schwartz for polyclonal antiserum directed to $\beta$ integrins, T. Hunter for the PDGFR- $\beta$-expression vector and polyclonal antibodies to the PDGFR $\beta$, B. Mayer for the pEBG mammalian GST-fusion expression vector and J.-L. Guan for the HA-tagged FAK $(\Delta \mathrm{C} 14)$ expression vector. This work was supported by National Cancer Institute, American Cancer Society and American Heart Association grants to D.D.S. D.J.S was supported by an NIH postdoctoral training grant; C.R.H by the Deutsche Forschungsgemeinschaft (HA-2856/1-1); D.I. by the UCSF Academic Senate; and C.H.D by the American Heart Association.

Correspondence and requests for materials should be addressed to D.D.S 


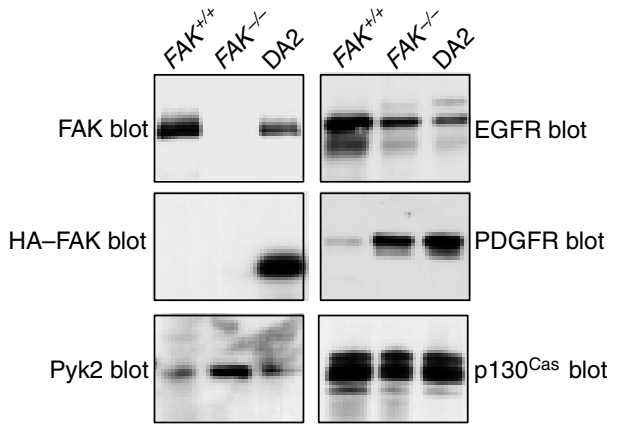

Supplementary Figure 1 Comparisons of the expression levels of FAK, Pyk2, EGF receptor (EGFR), PDGF receptor (PDGFR) and p130 $30^{\text {cas }}$ in $\mathrm{FAK}^{+/+}, \mathrm{FAK}^{-/-}$and DA2 cells. All cells are $p 53^{-1-}$.

Equal expression of EGFR and PDGFR in $F^{-/-}$and DA2 cells. In DA2 cells, the level of expression of haemagglutinin (HA-tagged) FAK was lower than in $F A K^{-1-}$ cells, whereas expression of Pyk2 was higher in $F_{A K}^{-1-}$ cells relative to DA2 and $F A K^{--}$cells (Fig. S1). Equal expression levels of the PDGFR or EGFR were detected in lysates of $F A K^{-1-}$ and DA2 cells (Fig. S1). Equal amounts of p130Cas were detected in $\mathrm{FAK}^{+/+}, \mathrm{FAK}^{-/}$and DA2 cells.

FAK but not Pyk2 is recruited to sites of integrin and EGFR clustering. To determine whether the specific recruitment of FAK to sites of integrin or EGFR clustering could be detected in intact cells, we used microbeads coated with BSA, fibronectin, or a combination of fibronectin and EGF as stimuli (Fig. S2). We used indirect immunofluorescence to observe the intracellular distribution of FAK in $F_{A K}{ }^{+/+}$and DA2 cells, and Pyk2 in $F_{A K K^{-/}}$cells. In $F A K^{+/+}$and DA2 cells, FAK localization is normally restricted to focal-contact regions at the basal surface, and this distribution did not change upon binding of control BSA-coated beads to cells (Fig. S2). Diffuse FAK staining appeared around fibronectin-coated beads attached to the apical surface of $F A K^{+/+}$cells, whereas streaks of FAK staining were observed around the attachment sites of EGF-coated beads (Fig. S2). Staining with antibodies to FAK and HA-FAK, in $F A K^{+/+}$ and DA2 cells respectively, showed redistribution of FAK around beads coated with fibronectin and EGF (Fig. S2). In contrast, bind-

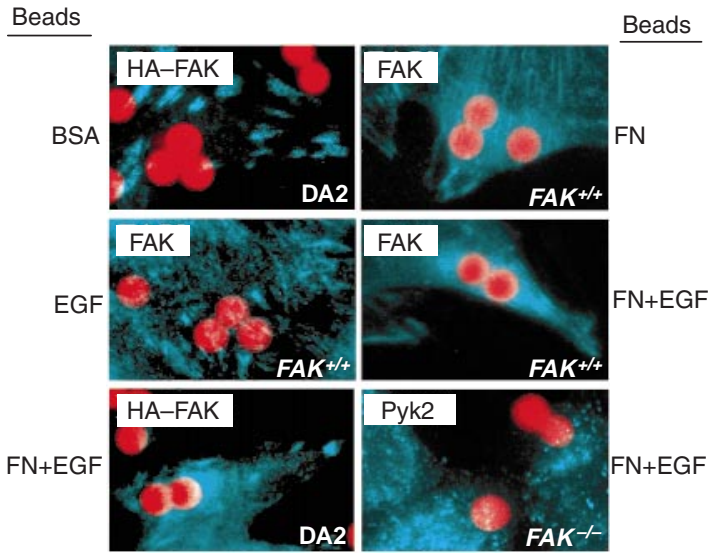

Supplementary Figure 2 In vivo recruitment of FAK to apical attachment sites of beads coated with fibronectin (FN), EGF or fibronectin and EGF (FN+EGF) in DA2 and $\mathrm{FAK}^{+/+}$fibroblasts. Pyk2 does not co-localize to sites of attachment to FN+EGFcoated beads in $\mathrm{FAK}^{-1-}$ fibroblasts. Bead size is $5 \mu \mathrm{m}$; antibody staining (upper left), and cells used (lower right) are indicated in each panel.

ing of beads coated with fibronectin and EGF to $F A K^{-/-}$cells did not promote a detectable redistribution of Pyk2 from its normal perinuclear distribution (Fig. S2). These results show that in intact cells, FAK can be recruited to sites of integrin and EGFR activation, and that it may have a function as a receptor-proximal component of both integrin and EGFR signalling pathways.

\section{Methods \\ Bead coating.}

M-500 Dynabeads (Dynal Inc., Oslo, Norway) were coated in $0.2 \mathrm{M}$ borate buffer, $\mathrm{pH} 8.5$, containing 1.25 $\mu \mathrm{g}$ BSA, fibronectin or EGF (Peprotech, Rocky Hill, NJ), or $1.25 \mu \mathrm{g}$ EGF and $0.625 \mu \mathrm{g}$ fibronectin. Beads were coated in rotating siliconized tubes for $24 \mathrm{~h}$ at room temperature. Remaining tosyl-groups were blocked by rotating for $4 \mathrm{~h}$ at $37^{\circ} \mathrm{C}$ with $0.1 \% \mathrm{BSA}$ and $0.2 \mathrm{M}$ Tris, $\mathrm{pH} 8.5$.

\section{Immunofluorescence.}

Coverslips were fixed $20 \mathrm{~min}$ after the addition of beads and treated as described ${ }^{15}$. FAK was observed using a cocktail of rabbit polyclonal anti-FAK antibodies, N-17 and C-20 (Santa Cruz). Pyk2 was observed using a cocktail of rabbit polyclonal antibodies, no. 5096 affinity-purified ${ }^{14}$ and Pyk2 N-19 (Santa Cruz). HA-tagged proteins were observed using rabbit polyclonal antibody Y-11 (Santa Cruz). 